\title{
Procedural Justice and Street-Level Sensemaking
}

We sought to understand whether, how, and with what consequences police managers would make use of information about the quality of officers' performance in managing their subordinates. To do so, we conducted semi-structured interviews with patrol officers and patrol supervisors that tapped their views with respect to the emphasis on customer service. The methodology is described in chapter 8. We analyzed their responses to understand their interpretations of the administrative priority, that is, the sense that they made of the push toward procedurally just policing. We begin with a discussion of sensemaking as an organizational phenomenon, and then turn to the qualitative data to extend the discussion to Syracuse and Schenectady in order to understand and interpret the complex reality behind efforts to translate into practice the top-down mandate of procedurally just policing.

\section{SENSEMAKING AND STREET-LEVEL RECEPTIVITY}

Police departments adopt new practices or programs such as community policing, Compstat, or democratic policing to meet instrumental goals. However, we know that the path from reform to implementation is far from straight. It is well documented in the policing literature that efforts to bring about change in policing often fall short of expectations (Rosenbaum and Lurigio 1994; Skogan 2008). Often, the "technical core"-in policing, the street-level work of patrol officers or detectives-is, in effect, buffered from the structures with which the work is not compatible. "[D]ecoupling enables organizations to maintain standardized, legitimating, formal structures while their activities vary in response to practical considerations," (Meyer and Rowan 1977, 357; also see Orton and Weick 1990). 
Organizations are "inhabited" by people, as one body of literature on institutional theory reminds us, and those people translate structural demands into practice. Police officers are particularly resistant to initiatives that involve civilians in defining their work or evaluating their performance (Skogan 2008). Furthermore, initiatives and new programs are less likely to be adopted when department leaders neglect to solicit officers' views about major issues of policy and practice and are not transparent. Officer cynicism is also a key element that drives employee resistance to change, seriously thwarting innovation in policing (Wykoff and Skogan 1994; Lurigio and Skogan 1994). Another force that shapes employees' willingness to be responsive to directives is the extent to which they are committed to the organization and internalize its values. As Beth Bechky observes, "It is clear that the most direct line into practice and meaning is the people doing the work and interpretation" $(2015,1163)$.

Uncertainty characterizes police life. Situations officers are tasked with handling are dynamic and ill-defined, direct supervision is uncommon, and the exercise of discretion is the norm. Organizational rules and regulations are developed to decrease the uncertainty that is characteristic of policing (Manning 1989). But organization theory tells us that people do not simply implement policies. Rather, they respond to the situations they face and their interpretations of these situations (Blumer 1969). Moreover, many policies and reforms (e.g., community policing, democratic policing, procedurally just policing) are replete with ambiguity leaving the members of police organizations to "interpret, label, enact, or otherwise make sense of innovations and reforms in their environment (Maguire and Katz 2006, 506). In an uncertain organizational environment, actors have the leeway to form their own interpretations as they seek to impose order and routines in order to carry out their duties. Karl Weick (1995) describes this as a process of "sensemaking" - making sense of or "structuring the unknown" (Waterman 1990, 4). When a reform is introduced, organizations and actors within must first define what they understand the reform to mean at a broad level and also for their everyday work life. How an organization's leadership sets the stage for reform and communicates expectations downstream (Gioia and Chittipeddi 1991), and the extent to which employees are able to understand the nature and purpose of the change (Lurgio and Skogan 1994; Amburgey et al. 1993) influence the extent to which reforms are adopted.

Employee support or resistance to reform efforts turns, in part, on the meaning actors attribute to the change (George and Jones 2001; Bartunek et al. 2006), particularly to the implications of change for improving or reducing the quality of their work life (Bartunek and Moch 1987). Where there is ambiguity, people interpret and insert their own understanding in order to translate policy into practice. Wesley Skogan describes the impact ambiguity can have on change efforts in this way: "Sergeants interpret the operational meaning of official policies at the street 
level, so when roles and rules are up for grabs, they have to have a clear vision they can support if change is really going to occur there" $(2008,25)$.

Thus, we found it productive to apply two concepts from organization theorysensemaking and loose coupling ${ }^{1}$ - to frame our understanding and discussion of the extent to which a quality management strategy was enacted in the study police departments. Weick introduced the concept of loose coupling in the 1970s. His examination of educational systems led him to posit that organizations cannot be understood in terms of their formal structure, goals, and functions. The different components of an organization are typically not tightly connected, creating uncertainty in the organizational environment and the need for adaptations. Weick (1976) notes several features of a loosely coupled system, including several means to reach the same end, lack of coordination, and limited regulation. We turn now to the feedback gathered through interviews with patrol officers and frontline police supervisors.

\section{Frontline Sensemaking}

From our interviews with patrol officers and supervisors in Syracuse and Schenectady, it appears that uniformed personnel strongly resisted neither administration's efforts to make police more customer-service oriented. However, even where managers and officers seemed willing to accept that customer service was an appropriate consideration in assessing police performance, there was some slippage in taking the measures of performance that we provided and actively managing them. The interviews we conducted with field supervisors and officers are useful in unpacking the thought processes around deciding what customer service meant for them, how it might impact their daily routine, and whether this implied a positive or negative change to their daily work. We would suppose that the conclusions to which officers came influenced decisions about how to act on management directives and, similarly, the conclusions to which frontline supervisors came would influence their reactions to upper management and also whether and how they assessed subordinates' performance in terms of the quality of their interactions.

The interpretive process of sensemaking is influenced by the setting of expectations. In our examination, it began when command staff conveyed their expectations to mid-level managers. The latter in turn then conveyed both their own expectations and their understanding of command staff expectations to their subordinate officers. Dennis Gioia and Kumar Chittipeddi use the term "sensegiving" to describe such efforts "to influence the sensemaking and meaning construction of others" (1991, 442).

Field supervisors and officers in our study used similar logic in assessing or making sense of the appropriateness of emphasizing the quality of police-citizen interactions. 
We turn now to a discussion of the factors involved in the interpretive process and that influenced resistance to or acceptance of the change. The two different ranks viewed the appropriateness of assessing police performance using nontraditional metrics, and made sense of "customer service" and "procedural justice," in similar ways. We detected little change in views between the two waves of interviews or across the two departments, so we combine interview responses from the two different time periods and departments, and note exceptions to these more general rules. We turn first to patrol officers' responses to a series of questions designed to understand how they interpreted and judged the administrations' efforts to assess their performance in terms of the quality of their interactions with the public.

\section{Patrol Officers}

Officers had mixed feelings about the appropriateness of the departments' emphasis on the importance of customer service: a number felt it was appropriate; others held that it was "appropriate but with a caveat"; and a third group believed the focus was not appropriate. These judgments shaped the extent to which officers resisted or accepted the departments' decision to measure and direct attention to the quality of the service they provide. They form a continuum of resistance, as shown in figure 12 below.

As respondents talked to us about the emphasis on the quality of their interactions with citizens, the starting point for many centered on the idea of conceiving of citizens in police encounters as customers or clients. Officers shared with us a range of reactions to the idea that a customer-service orientation should be applied to police work, and also to the appropriateness of making service quality the partial basis for assessing their performance. At one end of the continuum were those who expressed the view that their department's emphasis on service quality was appropriate. These officers did not find it troubling to think of the citizens with whom they interacted as consumers of a service the police provide. To them, the nature of the service police provide was compatible with a customer-service orientation, so the departments' emphasis was appropriate:

"We are there for the people and community. It would be unfair if we weren't treating people fairly or appropriately in accordance with the law."

"It [service quality] is very important. That is who we work for."

"Yeah, I think it is fair that they place an importance on it [service quality]. It's a service business."

"Yes, absolutely. ... If I called the police what would I expect from them. Regardless of station in life, treat everyone the same."

"Part of my performance is to help people. Even when I'm arresting people I say to them, 'Is there anything I can do to help you when you get out?' . . . There are certain things I have to do, but if you explain that to them then sometimes they'll say, 'I understand, Sir."' 


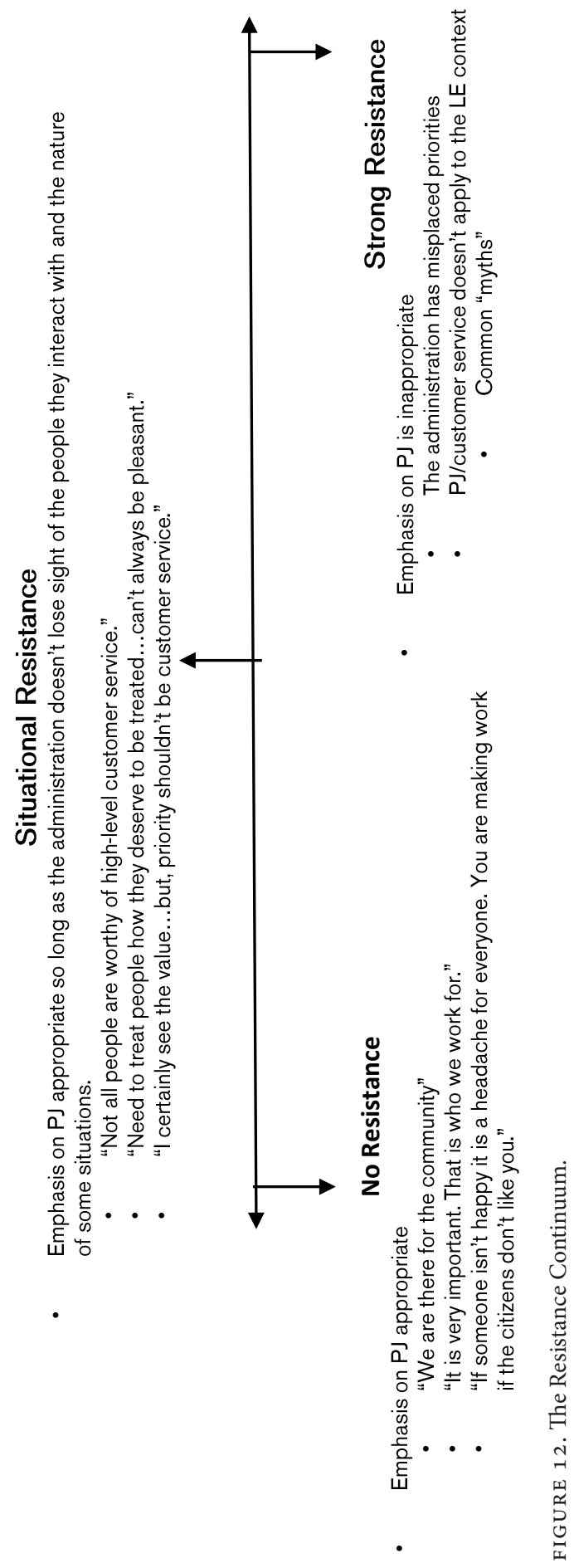


"We deal with everyone. All the victims and people with their cat in a tree, but you need to treat them all the same. Just because it is not an emergency to us, if they are calling us, it is to them."

Another set of officers expressed the same view that administrations' focus on customer service was appropriate but offered caveats. These officers are represented in the middle of the resistance continuum. Typically the caveat offered centered on the notion of citizens in police encounters being conceived of as customers and/ or lumping citizens into a single group. Officers talked about the importance of administrators and supervisors not losing sight of either the "types" of people with whom police interact or the nature of the situations. These officers were accepting of the decision to measure their performance in terms of the quality of their interactions as long as supervisors understood it wasn't reasonable to expect "highquality" service with all people or all situations. A theme that comes through here is the "we/they" mentality described as part of the police culture (Kaeppeler et al. 1998; Skolnick 1966):

"The emphasis is appropriate. You try to be as professional as you can, but at a point though you have to raise your voice. You try to be nice and polite, but some people don't get that."

"If you have decent people skills you won't have a large amount of complaints.... But, some individuals just aren't happy because they don't get what they want even if what they want isn't an option."

"Not all people are worthy of high-level customer service."

"Your action is dictated by their [citizens'] behavior."

On the far right of the resistance continuum were those officers who strongly opposed assessing their performance in these terms. The reasons they shared were similar to those described by officers who fell in the middle of the continuum. The difference between the two groupings of officers was that these officers saw no situations or circumstances under which to accept administrators' focus. Many believed that the concept of customer service was being inappropriately applied to policing. Disagreement was also rooted in the belief that the type of citizens with whom the police interact simply could not and would not ever be satisfied. These officers presumed that the nature or outcome of the encounter would be determinative of the citizen's subjective experience:

"We don't have customers so there is no customer service. It shouldn't apply. We aren't providers. The people we talk to don't want something. We [the police] need something. Who do we deal with? They don't call for no reason on a good day."

"I think the focus is overzealous. People call in complaints but some are not legitimate. Useless. Normally we deal with people on their worst day. We handle the call however we do. If I pulled you out of your home, how would you like it?"

"Administration has it as a high priority. They want to ... mend relationships as it has had a rocky road. Do I care? No. We aren't there for a good reason. We just put 
them in jail and ruined their life. People try to get out from under charges by saying things happened."

"It think it is stressed too much. Everyone knows the level of people we deal with. Not a lot of pleasant people. It is hard to react with politeness when people are abrasive and cursing."

"No because we are stuck between a rock and a hard place. People don't like us to begin with."

Another reason for the avowed skepticism and resistance to the emphasis on customer service was that it was perceived to symbolize the relative importance of the police force and the community, respectively: some officers inferred that citizens' concerns and citizen satisfaction were more important to the administration than in-house levels of satisfaction and morale. This group was also concerned that the departments' priorities were out of balance, believing that concern with citizen satisfaction outweighed the emphasis on fighting crime and disorder, enforcing the law, meeting victims' needs, and, of great concern, that it even outweighed concern for officer safety. The perceived failure of the administration to direct attention in-house was seen as a stressor and as a contributing factor to low morale:

"Need to boost morale. Happy employees would boost what we do out there, and they would have better customer service in the end."

"It's the public opinion department. Policy dictated by opinion. But we don't deal with the best of people."

"I am not looking for a pat on the back but just respect and not to be treated like a 'kid."

"It is all about pleasing the people. Not about us. That is their [command staff's] main concern."

"Focus so much on the public, they [the administration] forget about us. Patrol is underappreciated and always told to do more. The feedback to us is always negative. We do small things that administration doesn't see. They rush to judgment without asking what happened. They just assume we're wrong, and it's very stressful to work in this type of environment."

"It is too much. But I guess it is about PR.... There is too much non-police work. We are too soft."

"We treat suspects as innocent until proven guilty, but the uniform guy is guilty until proven innocent. It's how the department treats you."

"Everyone here should be able to treat people with respect but not at the expense of officer safety. We could be right but management doesn't see it that way. Officers should come first."

"It should be ... public safety, then my safety, then customer service. Not gonna [sic] compromise my safety for customer service."

"I certainly see the value . . but, priority shouldn't be customer satisfaction. It should be a second priority. Safety of people and yourself is first."

"In some respects they [administration] put the emphasis in the wrong place. They need to worry more about the true victims and less about the people that don't 
deserve it. We need more emphasis on true victims than the perceptions of a wife beater. Who cares what he thinks?"

Research tells us that the sensemaking and sensegiving processes are iterative (Gioia and Chittipeddi 1991). Indeed, we found support for our hypothesis that as experience accumulated and allowed supervisors and officers to assess the actual impact that managing the elements of procedural justice had on their day-to-day work, their early perceptions might change. We had only some of the same respondents in the two waves of interviews, so we can only make cautious comparisons about the predominant themes that emerged in wave 1 interviews, compared to wave 2. The most meaningful difference we detected between the interviews conducted at the outset of the project compared to those at the conclusion of the project was in the prevalence of officers who seemed outright resistant to their department's emphasis on customer service and the appropriateness of assessing their own performance in these terms. Concerns appeared to diminish over time. It would seem that uniform personnel were girded to offer some resistance, but that resistance may have diminished as officers realized that the heightened emphasis amounted to no meaningful change in their everyday work life. It was loosely coupled. Moreover, it seemed that with the passage of time, officers were more at ease with supervisors' ability to be fair-to treat them in a procedurally just manner-when making decisions about the quality of the service officers delivered. In wave 2, some respondents who touched on the argument that you cannot expect all people to be "happy" went on to give command staff and supervisors credit for differentiating "real" complaints from "false" and giving officers the benefit of the doubt. Of course, the difference between waves might also simply be the result of interviewing different people in each wave.

"Command staff understand who we are dealing with. Upset people that go to jail whether an officer has done them wrong or not.... They [command staff] accurately assess the situation and the citizen complaining."

\section{Frontline Supervisors}

Frontline supervisors can play a key role in efforts to bring about organizational change. Therefore, as we did with officers, we explored sergeants' views on the appropriateness of viewing the quality of police service delivery through a customerservice lens. Perhaps not surprisingly, since sergeants are only one step removed from officers, we found consistent themes when we compared officers and sergeants' responses.

A handful of frontline supervisors expressed the view that a customer-service orientation "fit" when applied to police work and stated they were receptive to assessing performance in those terms. Many supervisors went further and identified pragmatic reasons to support the administration's focus. This additional source of support was more common among sergeants compared to officers. 
For examples: community support makes the job easier; it lowers the chances of getting a complaint filed against you or a subordinate; and it helps to build a supply of support from the community into which they may need to tap.

"Part of why we are here is to help the public, and if we treat them with the respect they are due, they are more apt to help us with future investigations."

"If someone isn't happy it is a headache for everyone. You are making work for the sergeant if the citizens don't like you."

"With an enlightened department, such as us, it starts in the academy. I see more kids being taught that this is how you do things, as opposed to a run-and-gun show. Your job is harder if the citizen isn't satisfied. If you start out screaming and yelling, it is hard to go down. You can always escalate, but it is hard to go the other way."

"Sure, bottom line here is service to the public. They are our employers. We are here to serve the public like any business. The fact that you can satisfy people is important. You need to maintain your role and enforce the law. Some won't be happy about it, but that's the way it is. Ten people at a call, and five are happy. I think that is a success."

Just as some officers were guarded in their willingness to embrace fully the decision to assess police performance in terms of service quality so, too, were frontline supervisors. A group of frontline supervisors said that they would support their commanding officers' directives to assess the quality of subordinates' interactions with the public in these terms, so long as the administration understood that not all people or situations would allow for equal service quality, and, in addition, they would also need to take into account factors they judged to influence citizens' perceptions, but that were outside the control of the officer in the immediate situation (e.g., response time, policy/law, global views about police):

"Need to treat people how they deserve to be treated ... can't always be pleasant and respectful."

"Customer service is low because of call volume. ... You try to address people's issues but they get lost because no one can get back to them."

"Too much sometimes. A lot could be solved with manpower. They want to cut back money, but they want customer service, but officers are there on calls and have two or three more holding. People want and expect something, but the officers are overworked, and the people they deal with are belligerent half the time."

"Yes, to an extent. You have to realize that people they [officers] interact with might not be happy with you."

Frontline supervisors offered rationales for resisting an emphasis on procedural justice that were very similar to those expressed by officers on the far right of the resistance continuum. Supervisors here indicated that they believed the idea of conceiving of a citizen in a police encounter as a customer was inappropriate, which in turn colored their view of their department's move to assess performance in terms of the quality of the police-citizen encounter. Others did not buy into this 
proposition because they recognized that the citizens with whom their subordinates interact bring to the encounter preconceived views about police that would color citizens' judgments of the officer in the immediate encounter, yet might have little connection with what the officer actually did. As we heard with officers, some sergeants portrayed the administration's decision to fold measures of citizen satisfaction into assessments of police performance as one that prioritized the views of external customers over internal customers and would result in negative outcomes:

"No. We are not in a customer-service business. We have a job to do. We are meeting with people when something is wrong so they aren't happy anyway. ... I think no one is happy with us anyway. ... People don't like the police.... I feel you would get bad ratings no matter how you do your job."

"Customer service? We don't charge for our service. I don't understand the question. This isn't a fair question. . . . No one calls the police to say hello. We only see them at their worst. We are in an uphill battle. All the smiles and service doesn't make people happy. ... You can't compare law enforcement to anything else. It is not a counter at the mall."

"There is a fine line between customer service and having the edge to do the job correctly. We are more customer-service-based here than a PD [should be]."

"We aren't going to make everyone happy. We aren't doing our job if everyone is happy. We have to protect people's safety."

"Do they worry about the guys? They need to worry about the guys. Patrol takes a beating. ... We need less emphasis on customer service. I shouldn't be looking at my job saying I only have $x$ more years to go. I love my job, but it has been a long $x$ years."

"They are very concerned with public views of the agency and don't seem to worry about combatting crime ... It is important, but the core mission should be to police. We need to solve and reduce crime."

"I don't think it is the most intelligent thing from a police or administration view. Don't focus on customer service because then safety becomes less important. Focus on the end product, which is us [patrol]. Whether people are safe. The humans that work for you are just as important as people [citizens]."

\section{Officers' Perceptions of Supervisors Buy-In}

We expected variation in the extent to which frontline supervisors agreed with the top-down directive to manage subordinates' performance in terms of procedural justice. And, indeed, that variation emerged in their descriptions of how they felt about the directive. This variation was further corroborated in themes that emerged in officers' discussion about the extent to which they detected differences in the message conveyed by different sergeants regarding the importance of customer service. We turn now to a discussion of how officers perceived sergeants to differ in terms of buy-in to the customer-service-oriented approach adopted by the departments. 
Officers attributed some of the variation in the message supervisors delivered about the importance of customer service to individual supervisors' orientations up or down the chain of command. Some were tapping into a perception that alignment with officers versus mid-level management, or "the streets" versus "the administration," influenced supervisors' perceptions:

"Half and half [buy-in]. Direct supervisors understand our way of thinking and they separate us from the administrative side."

"Varies per shift. Some are in the back seat of the administration, so it's important, but as you get further from administration they don't care as much."

"They were in our shoes too, and they know it is tough. There is a lot of situational customer service."

"It trickles all the way down. Sergeants see more of what we go through, so they are more sensitive than their higher-ups."

"Different by old school policing versus new school policing. The old school still pushes that you do what you want to, what you know, and you are in charge. New school is that you listen more. You see this across supervisors."

"Patrol supervisors are still on the road 'obviously the shit rolls downhill. So they are in a hard position.' They need to keep it as real as possible, 'but the street is the street."”

Others did not detect much variation across supervisors, nor did they expect that what supervisors really thought would matter. They presumed that if command staff ordered frontline supervisors to focus on this aspect of performance, the latter would fall in line, given the nature of police organizations.

\section{SUMMARY}

Our intention was to understand officers' and frontline supervisors' views on the appropriateness of their administration's emphasis on procedurally just policing and assessing police performance in these terms. Our findings are consistent with the research that suggests that the fairness officers attribute to their organizational environment influences their own willingness to embrace service-oriented policing (Myhill and Bradford 2012). Consideration of internal procedural justice emerged as a factor for officers. They expressed resistance to the external focus on fairness and satisfaction because they felt the administration failed to take account of internal satisfaction. Others believed the external orientation would come at an expense; it would detract, for example, from community safety, officer safety, and concern and care for victims. Our findings are consistent with research that has found connections between officers' sense of "organizational justice" - that is, officers' perceptions of the procedural justice with which their superiors treat them-and officers' acceptance of and compliance with organizational rules and regulations (Tyler 2011; Skogan et al. 2014; Wolfe and Piquero 2011; Trinker et al. 
2014). Employees who believe that they are treated in a procedurally just manner are more likely to identify with and support the organization and its values (Tyler and Blader 2003; Bradford and Quinton 2014). How strongly officers' perceptions of organizational justice are rooted in the actual practices of their organizations is an open question, but since their perceptions are real in their consequences even if they are ill-founded, their perceptions are important.

Judgments made by uniformed personnel about the soundness of assessing police performance in terms of citizens' subjective experiences also turned to a large degree on the nature of the citizens with whom officers interacted and the types of events that brought them together. For some, this did not preclude them from finding some value in measuring police performance in these terms, so long as managers and the highest levels of administration did not lose sight of "the streets." For others, however, citizen satisfaction and customer service were viewed as ill-fitting in the law-enforcement context, given the police task and the nature of their "clientele." It was clear from these comments that the underlying presumption was that citizen satisfaction had to compete with other departmental priorities. Most respondents indicated no awareness that research tells us that citizen satisfaction could assist in achieving goals of crime control, citizen cooperation, and citizen compliance-and thus officer safety.

The themes of this chapter reflect the sensemaking process. Both internal and external factors emerged as influential in either thwarting or supporting efforts to bring about change. We turn next to a review of the principal findings of our research and their implications. 